\title{
THE COSTS OF WORKPLACE INJURIES AND WORK- RELATED ILL HEALTH IN THE UK
}

\author{
Dr Stavros Georgiou, Chemicals Regulation Directorate, UK Health and Safety \\ Executive, stavros.georgiou@hse.gsi.gov.uk \\ Michael Thomson, Economic Analysis Unit, UK Health and Safety Executive, \\ michael.thomson@hse.gsi.gov.uk \begin{abstract}
Executive, anna.richardson-owen@hse.gsi.gov.uk
Heidi Edwards, HSE Statistics Branch, UK Health and Safety Executive, heidi.edwards@hse.gsi.gov.uk
\end{abstract} \\ Anna Richardson-Owen, Economic Analysis Unit, UK Health and Safety
}

\begin{abstract}
The UK Health and Safety Executive (HSE) produces aggregate estimates of the costs to Britain of workplace accidents and work-related ill health which are used for a range of public policy purposes. HSE also produces estimates of the unit cost to society of individual workplace injury accidents and work-related ill health. Ongoing work within HSE's Economic Analysis Unit (EAU) has however revealed limitations with the current methodology and sources of data used to derive the estimates. HSE has commissioned a project to produce new estimates of these aggregate and unit costs, which attempt to overcome the current problems with the estimates. The paper will discuss the background to the work, its aims and objectives, and the methodology proposed.
\end{abstract}

Key Words: Workplace injuries, ill health, costs, safety.

\section{INTRODUCTION}

The issue of worker health and safety in public and private sector allocative decision making is an important one for obvious reasons. It is tempting to think that health and safety should always come first in any decisions involving risks to human health and safety. However since resources are scarce, individuals, employers and society have to make choices between health and safety and other competing wants. Given that health and safety is a normal good, the 
Stavros GEORGIOU, Michael THOMSON,

Anna RICHARDSON-OWEN and Heidi EDWARDS

choice of the optimal level of health and safety is a decision concerning the appropriate trade-off between competing uses of scarce resources. Economists look at how scarce resources are allocated between competing wants and argue that the most appropriate way of taking account of health and safety in decisions about preventive measures and regulation of risk from work activities is by placing a monetary value on the costs of work related injuries and ill health. In their efforts to reduce harm within society, the government and its partners need to identify where the greatest burdens of health and safety failures fall. Estimates of the costs to the key stakeholders can help. Although the estimates can never show how easy or successful attempts to reduce harm might be, they nevertheless provide a good starting point from which to analyse the problems.

In this respect, the UK Health and Safety Executive (HSE) estimates the aggregate costs to Britain of workplace accidents and work-related ill health, as well as estimates of the unit cost to society of individual workplace injury accidents and work-related ill health. Recent work within HSE's Economic Analysis Unit (EAU) has however revealed limitations with the current methodology and sources of data used to derive the estimates. The purpose of this paper is to report on ongoing work to revise the current estimates of aggregate and unit costs of work place injury accidents and work related ill health in Britain. The current methodology and data are briefly reviewed before going on to consider the aims, objectives and proposed methodology of a recently commissioned project to produce new estimates of the aggregate and unit costs that overcome the current problems.

\section{BACKGROUND}

\section{Aggregate Cost Estimates}

The Health and Safety Executive (HSE) first produced estimates of the costs to Britain of workplace accidents and work-related ill health for 1990 (Davies \& Teasdale, 1994), separately identifying costs to the individual, to the employer and to society as a whole. These estimates were updated to 1995/96 (Gordon et al, 1999), with an interim update for 2001/02 providing the most recent estimates.

The cost estimates of workplace accidents and work-related ill health are used for a range of purposes by HSE and other stakeholders, including:

- To inform strategic policy and new programme development

- To evaluate the impact of HSE and to provide evidence to the Treasury during spending reviews.

- To address queries from within HSE, other government departments, the press, private sector organisations, employer organisations, trade unions, academics and the public. 
The wide usage of these cost estimates highlights their importance both within and outside of HSE. It is therefore essential that the underlying methodology is robust and the most appropriate data is utilised.

\section{Aggregate Cost Categories}

HSE has traditionally estimated costs for three types of stakeholder: individuals, employers and society. Figure 1 describes the different categories that make up the total costs for each of these stakeholders.

The total costs to individuals, employers and society are among the most commonly quoted "Costs to Britain" estimates. The 2001/02 interim estimates are presented in Tables 1 to 4 . As well as costs to the three "traditional" stakeholders mentioned above, the costs to the economy are also presented. These bear the closest relationship to the costs to society, the only difference being that the costs to the economy exclude the human costs of pain, grief and suffering.

\section{Table 1 - Costs to individuals}

\begin{tabular}{|l|l|}
\hline Costs to individuals & fbillion \\
\hline Total & 10.1 to 14.7 \\
\hline III health & 5.9 to 9.4 \\
\hline Injury & 3.3 to 6.3 \\
\hline
\end{tabular}

Table 2 - Costs to employers

\begin{tabular}{|l|l|}
\hline Costs to employers & fbillion \\
\hline Total & 3.9 to 7.8 \\
\hline III health & 1.5 \\
\hline Injury & 1.0 to 1.1 \\
\hline Non-injury & 1.4 to 5.3 \\
\hline
\end{tabular}


Stavros GEORGIOU, Michael THOMSON,

Anna RICHARDSON-OWEN and Heidi EDWARDS

\section{Figure 1}

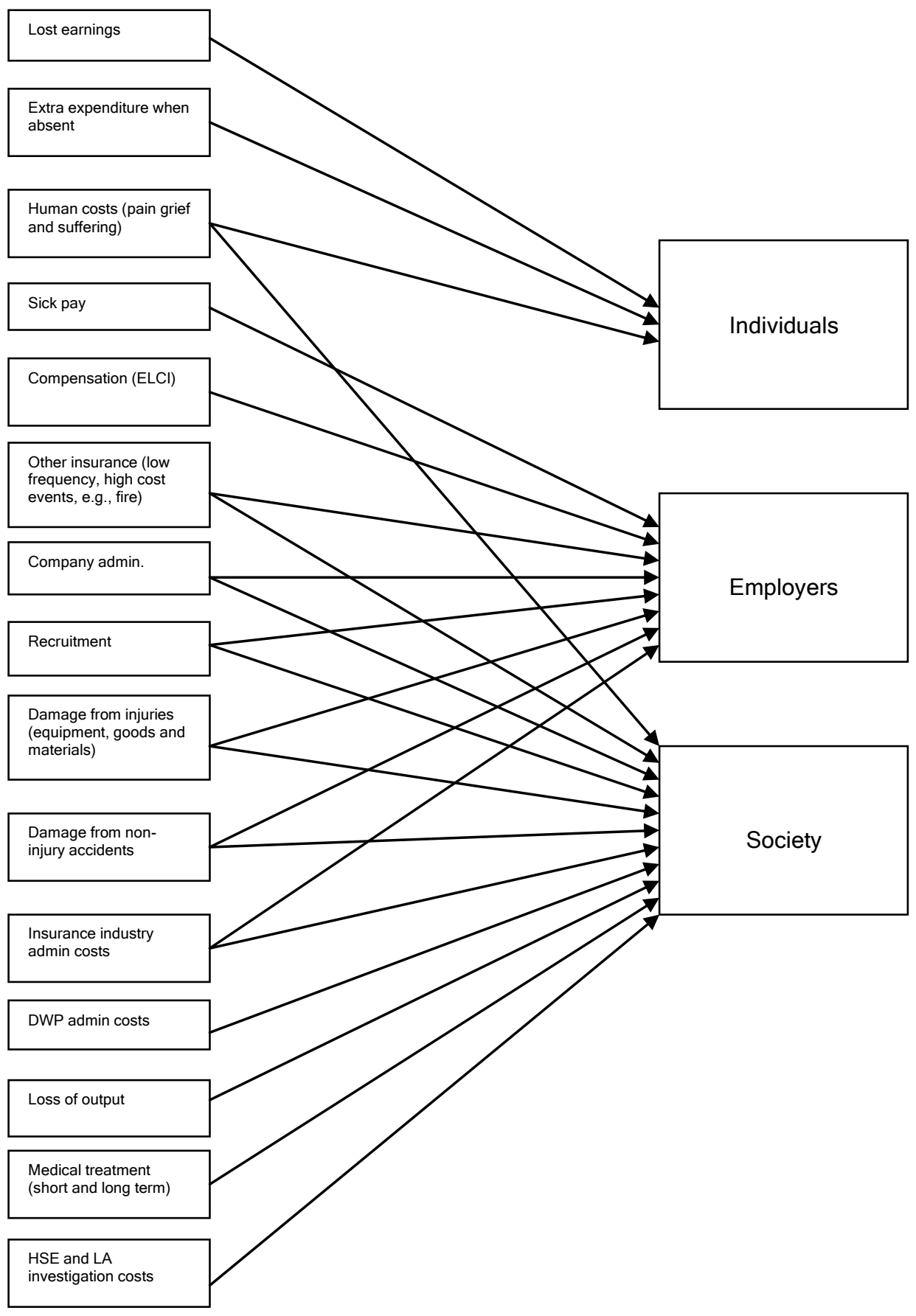


Table 3 - Costs to society

\begin{tabular}{|l|l|}
\hline Costs to society & fbillion \\
\hline Total & 20.0 to 31.8 \\
\hline III health & 11.3 to 17.3 \\
\hline Injury & 5.9 to 10.7 \\
\hline Non-injury & 1.4 to 5.3 \\
\hline
\end{tabular}

Table 4 - Costs to the economy

\begin{tabular}{|l|l|}
\hline Costs to the economy & £billion \\
\hline Total & 13.1 to 22.2 \\
\hline III health & 7.6 to 11.6 \\
\hline Injury & 3.2 to 6.2 \\
\hline Non-injury & 1.4 to 5.3 \\
\hline
\end{tabular}

\section{Unit cost estimates}

HSE also produces estimates of the unit cost to society of individual workplace injury accidents and work-related ill health. These are referred to as the Economic Analysis Unit (EAU) Appraisal Values, and are used to value the benefits of HSE interventions for the purpose of impact assessments. The most recent estimates available (see table 5) are for $2006(\mathrm{Q} 3)^{1}$. The EAU appraisal values give the unit costs to society for three kinds of workplace accidents and ill health:

- Fatalities;

- Non-fatal injury accidents, including:

- Major injury

- Other reportable injury (over 3 days)

- Minor injury;

- An average case of ill health.

In all three categories the overall unit cost to society of an incident is divided into its component costs:

- Human costs;

- Cost of lost output; and

- Resource costs. 
Stavros GEORGIOU, Michael THOMSON,

Anna RICHARDSON-OWEN and Heidi EDWARDS

Table 5 - 2006 (Q3) EAU appraisal values

\begin{tabular}{|c|c|c|c|c|}
\hline & $\begin{array}{c}\text { Human } \\
\text { cost }\end{array}$ & $\begin{array}{l}\text { Lost } \\
\text { output }\end{array}$ & $\begin{array}{l}\text { Resource } \\
\text { costs }\end{array}$ & Total \\
\hline Fatality & $£ 991,200$ & $£ 520,700$ & $£ 900$ & $£ 1,500,000$ \\
\hline Major injury & $£ 18,400$ & $£ 16,200$ & $£ 5,800$ & $£ 40,500$ \\
\hline $\begin{array}{l}\text { Other reportable injury } \\
\text { (O3D) }\end{array}$ & $£ 2,700$ & $£ 2,600$ & $£ 500$ & $£ 5,800$ \\
\hline Minor injury & $£ 200$ & $£ 100$ & $£ 50$ & $£ 350$ \\
\hline Average case of ill health & $£ 6,700$ & $£ 2,700$ & $£ 800$ & $£ 10,100$ \\
\hline
\end{tabular}

Human costs include the cost of "pain, grief and suffering to the casualty, relatives and friends, and, for fatal casualties, the intrinsic loss of enjoyment of life over and above the consumption of goods and services". For fatalities, these are based on the UK Department for Transport value of preventing a fatality (VPF), whereas for nonfatal injuries and illness the Davies et al (1999) estimates are used.

The costs of lost output are assumed to be "equal to the labour cost that is normally incurred in employing the absent worker, plus any sick pay". It is assumed here that the firm does not suffer any decline in output as suitable arrangements to maintain output are made. The "lost output" appraisal values are based on estimates from Davies et al (1999).

The resource costs include property damage, administration, recruitment, HSE and local authority investigation costs, and medical treatment. The "resource costs" appraisal values are based on estimates from Davies et al (1999).

As a result of the fact that the EAU Appraisal Values combine estimates from the Department for Transport, Davies \& Teasdale (1994) and in-house EAU methodology, the process of estimation lacks consistency. More importantly the Appraisal Values only estimate the cost of work-related injury and ill health to society, unlike the aggregate cost to Britain estimates, which value the costs to the individual, the employer and to society. Thus, the current methodology does not allow for the aggregation of the unit Appraisal Values into the cost to Britain 
estimates. This reduces the traceability and transparency of the process and increases the resource burden associated with updating the aggregate estimates. Consequently, the aggregate estimates are not updated annually, as is the case with the unit values.

\section{AGGREGATE AND UNIT COST ESTIMATES: METHODOLOGICAL \& DATA PROBLEMS}

Several problems have been identified with the current methodology and data for calculating both the unit and aggregate cost estimates. A summary of the current issues for the unit appraisal values and aggregate estimates follows respectively:

\section{EAU Appraisal Values}

Firstly, as mentioned earlier, the unit cost of injuries and ill health are estimated for society only. The unit costs to individuals and employers are not estimated, such that there is no consistency with the aggregate values.

Second, the EAU Appraisal Values classify non-fatal injuries as: minor (here defined as requiring absence of three days or less from work), other reportable (here defined as requiring over three days absence) and major (here defined as requiring over three months absence). However, these classifications are not the same as the RIDDOR classifications (Riddor, 1995), which are used in the aggregate estimates (see later).

Third, work-related ill health is simply classified as the average case of ill health.' By definition, this covers a spectrum of severity and suffering, so creating a wide range of costs to the individual, the employer and society;

Fourth, injury data is sourced from a module of questions included annually in the national LFS, which counts the number of people injured at work in a year, (rather than the number of injuries sustained in a year). If an individual is injured more than once in a year, only their most recent injury will be counted. This leads to a likely underestimation of the total number of injuries. Data from 2006/07 suggests about a fifth of individuals reporting a work-related injury (including road traffic accidents) actually suffered more than one injury during the year (though it is likely that some of these additional injuries will be as a result of road traffic accidents which is outside HSE's jurisdiction);

Fifth and similarly to the above, ill health data is obtained from the same source and so counts the number of people suffering work-related ill health as opposed to the number of cases of ill health suffered in the year. The most serious case of ill health, including all episodes during the year, is recorded as opposed to the most recent. In $2006 / 07$ about $15 \%$ of individuals reporting a work-related 
Stavros GEORGIOU, Michael THOMSON,

Anna RICHARDSON-OWEN and Heidi EDWARDS

illness actually reported suffering more than one work-related illness during the year;

Sixth, for historical reasons, it has been necessary to estimate the cost of ill health using prevalence from a module of questions included annually in the Labour Force Survey, (LFS) ${ }^{2}$. Prevalence is the (stock) measure of the number of people suffering from an ill health condition in a population at any given point in time and so includes recurring ill health events stemming from past working conditions. As such it will not capture the costs associated with new cases of work related ill health (stock versus flow measure);

Seventh, the costs associated with permanent incapacity (or 'never returns') accounts for approximately $50 \%$ of the estimated cost of work-related ill health. The 2001/02 interim update uses, for its estimate of 'never returns', data from a one off EUROSTAT questionnaire module included in the LFS in 2002. Questions were included in the 2004/05 LFS to estimate the number of 'never returns'. However these questions did not perform satisfactorily. New, improved questions, designed to estimate the total number of never returns, will be included in the LFS in 2008/09;

Recruitment cost estimates are based on 'bringing forward' recruitment costs by an average of three years when an employee is forced to leave the labour force, based on methodology in Gordon et al, (1999). Recruitment costs include the costs of replacement due to permanent incapacity and also temporary replacement for absence over 6 months.

\section{Aggregate estimates}

First, as already discussed aggregate estimates are made of the total costs to the individual, to the employer and to society (see Appendix A). Disaggregated costs by industry, region and occupation are calculated through a top down approach. However, due to differences in methodology and presentation of costs, the aggregate cost estimates are independent of the unit cost estimates;

Second, ill health data is sourced from the LFS module and so is subject to the understatement problems as noted for the unit appraisal values;

Third, injuries are categorised as follows: permanent incapacity, serious or major (involving between 2 and 7 days in hospital, some restriction to work and leisure for several months and return to normal health after three to four months); non-serious reportable, (over 3 days absence); minor injury (involving up to 3 days absence); and non-injury. The costs of ill health are estimated in Gordon et al (1999) for just the one category, general work related illness;

Fourth, historically, aggregate cost estimates have been based on prevalence data (see earlier); 
Fifth, 'never returns' account for a large proportion of the costs yet the data source for never returns is outdated and uncertain;

Sixth, recruitment costs are calculated based on the principle of 'bringing forward' the cost of recruitment by three years for employees who are forced to leave the labour force (Gordon et al, 1999). Uniquely to the aggregate estimates, a recruitment chain is assumed of between one and four people, and unlike with unit cost estimates, no account is taken of temporary replacement costs or re-deployment costs within the same organisation.

\section{REVISION OF AGGREGATE AND UNIT COST ESTIMATES}

Based on the issues and problems in the methodology and data sources suggested in the previous section, the HSE has commissioned a project to revise the aggregate and unit cost estimates. The project will seek to identify and implement methodological improvements and/or additional data sources which will improve the process. Principally, the work will aim to disaggregate both unit and aggregate costs into the costs to individuals, employers and society, as well as disaggregating the aggregate cost estimates by industry, region and occupation. In this respect it is hoped to develop a spreadsheet model which can be used in-house on an annual basis to produce the aggregate and unit cost estimates in the future.

Specific suggestions for the way ahead on revising the unit cost estimates include the following:

The work will seek to analyse the unit costs of injury and ill health to both individuals and to employers as well as to society, to ensure consistency with aggregate values.

It will explore different techniques for valuing the cost of injuries and ill health. For example it will look at the possible application of Quality Adjusted Life Years. In addition it will critique the current technique for valuing injuries based on Department for Transport's Value of Preventing a Fatality (VPF) values, and suggest an alternative if one can be found.

The work will explore the feasibility of a different approach to valuing ill health. For instance it may be possible to have separate solutions for the three categories covering the most commonly reported ailments: musculoskeletal disorders; stress; and 'other'. LFS data can support this. Consideration could also be given to the further breakdown of ill health categories by duration of the period of ill health.

With regards to the problem of underreporting of injuries, the work will consider uprating LFS data to reflect the number of injuries / ill health events in the year, rather than the number of people who suffered from at least one injury / ill health event in the year. 
Stavros GEORGIOU, Michael THOMSON,

Anna RICHARDSON-OWEN and Heidi EDWARDS

In order to capture the costs associated with new cases of work related ill health, the work will consider replacing the LFS prevalence estimate with the incidence estimate, (being the number of new cases of ill health arising in any year). Thought will need to be given as to how to capture any future ill health costs resulting from these new cases of ill health (it may be arguable that prevalence could act as a proxy to capture current and future costs arising from new cases of illness, albeit possibly a biased one, given that estimates based on prevalence will include costs of work-induced ill health resulting from past events).

The work will also consider the appropriateness of alternatives to LFS data for 'never returns'. For example, Pathak (2008) derives 'never returns' from the 'Routes onto Incapacity Benefit' (ROIB) survey 2007 (Kemp and Davidson, 2008). However, this data source will not include all persons who have permanently left the workforce on the grounds of ill health, but only those who claim incapacity benefit. In addition, the ROIB survey is not repeated annually and so will become less relevant for estimates in future years.

The methodology for estimating recruitment costs will be reconsidered in order to ensure consistency with the methodology for aggregate values. Consideration of ranges to the unit cost estimates (i.e. confidence intervals arising out of the uncertainty of the survey data) will also be made so that the aggregate values (cost to Britain estimates) can be reported over a range of values also. This will demonstrate that the estimates are subject to uncertainties, although the range will only reflect the uncertainties arising from the use of survey data rather than uncertainties surrounding the assumptions underpinning the model.

With regard to suggestions for improving the aggregate costs estimates, the work will seek to adopt a bottom up methodology, with aggregate costs being the sum of the unit values, taking care to avoid potential areas where costs to the individual, the employer and to society overlap.

The work will also consider in respect of the aggregate estimates, the suggestions made above for the unit costs in relation to the understatement of the LFS module, the categorisation of injuries and ill health, the choice between prevalence and incidence data and the source of never returns data.

It will be necessary to take care to ensure that confidence intervals at the disaggregated level are handled appropriately. Whilst for example the regional central cost estimates will sum to the cost to Britain central estimate, this is not true of the confidence intervals. (At more disaggregated levels there will be less confidence in the estimates which will result in a widening of the associated confidence interval). 
It is anticipated that the work will be completed by December 2009 with cost estimates for both unit and aggregate values published by the end of December 2009.

\section{CONCLUSIONS}

The HSE has published three estimates of the cost of Britain of workplace accidents and work related ill health. The first two estimates were for 1994 and 1999 , and the third was an interim update for 2001/2. In all three publications, the costs were divided into three categories: the costs to individuals, the costs to employers and the costs to society. These estimates of costs are used for a number of important purposes by the HSE and other stakeholders, in particular for evaluating measures to reduce injuries and ill health in the workplace, both at employer (micro) and policy (macro) level. This paper has reviewed the current estimation of unit cost and aggregate costs and outlined some of the current problems with the estimates. A project has been commissioned to produce new estimates of these aggregate and unit costs, which attempt to overcome some of these problems. Possible improvements that the project may consider in deriving revised estimates were discussed. Revised estimates based on an updated methodology will be published on the HSE website in the near future.

\section{END NOTES}

(1) EAU Appraisal Values. http://www.hse.gov.uk/economics/eauappraisal.htm

(2) Self Reported Work-related IIIness (SWI) and Workplace Injuries in 2006/07: Results from the LFS Survey. http://www.hse.gov.uk/statistics/lfs/lfs0607.pdf

\section{REFERENCES}

Davies, N.V. \& Teasdale, P, (1994). The Costs to the British Economy of Work Accidents and Work Related III Health. HSE Books ISBN 071760666 X

Gordon, F., Risley, D., \& EAU economists, (1999). The Costs to Britain of Workplace Accidents and Work Related III Health in 1995/96. Second Edition. HSE Books ISBN 071761709 2; Interim update available at: http://www.hse.gov.uk/statistics/pdf/costs.pdf.

Pathak, M., (2008). "The Cost to Employers in Britain of Workplace Injuries and Work Related III Health in 2005/06," http://www.hse.gov.uk/2008/09/11/cost-ofworkplace-injuries-and-ill-health

Binch, S.,and Bell, J., (2007). "The Cost of Non-Injury Accidents". Health and Safety Laboratory. http://www.hse.gov.uk/research/rrhtm/rr585.htm 
Stavros GEORGIOU, Michael THOMSON,

Anna RICHARDSON-OWEN and Heidi EDWARDS

RIDDOR (1995) "The Reporting of Injuries, Diseases and Dangerous Occurrences Regulations". http://www.hse.gov.uk/statistics/sources.htm\#riddor

Kemp, P.,\& Davidson, J., (2008). "Routes Onto Incapacity Benefit: Findings From a Survey of Recent Claimants". Commissioned by the Department for Work and Pensions, (DWP). http://www.dwp.gov.uk/asd/asd5/rports20072008/rrep469.pdf 